\title{
Evaluation of active ingredients and larvicidal activity of clove and cinnamon essential oils against Anopheles gambiae (sensu lato)
}

Adelina Thomas ${ }^{1}$, Humphrey D. Mazigo ${ }^{2}$, Alphaxard Manjurano ${ }^{3}$, Domenica Morona ${ }^{2}$ and Eliningaya J. Kweka ${ }^{2,4^{*}}$

\begin{abstract}
Background: Mosquitoes are well-known vectors of many diseases including malaria and lymphatic filariasis. Uses of synthetic insecticides are associated with high toxicity, resistance, environmental pollution and limited alternative, effective synthetic insecticides. This study was undertaken to evaluate the larvicidal efficacy of clove and cinnamon essential oils against laboratory Anopheles gambiae (sensu stricto) and wild An. arabiensis larvae.

Methods: The standard WHO guideline for larvicides evaluation was used, and the GC-MS machine was used for active compounds percentage composition analysis and structures identification. Probit regression analysis was used for $L C_{50}$ and $L C_{95}$ calculations while a t-test was used to test for significant differences between laboratoryreared and wild larvae populations in each concentration of plant extract.

Results: Mortality effect of clove and cinnamon essential oils against wild and laboratory-reared larvae had variations indicated by their $\mathrm{LC}_{50}$ and $\mathrm{LC}_{95}$ values. The mortality at different concentrations of cinnamon and clove post-exposure for wild and laboratory-reared larvae were dosage-dependent and were higher for cinnamon than for clove essential oils. The mortality effect following exposure to a blend of the two essential oils was higher for blends containing a greater proportion of cinnamon oil. In the chemical analysis of the active ingredients of cinnamon essential oil, the main chemical content was Eugenol, and the rarest was $\beta$-Linalool while for clove essential oil, the main chemical content was Eugenol and the rarest was Bicyclo.

Conclusion: The essential oils showed a larvicidal effect which was concentration-dependent for both laboratory and wild collected larvae. The active ingredient compositions triggered different responses in mortality. Further research in small-scale should be conducted with concentrated extracted compounds.
\end{abstract}

Keywords: Anopheles gambiae, Larvicides, Mortality, Essential oil, Clove, Cinnamon

\section{Background}

Vector-borne diseases remain a major public health concern in tropical areas [1]. Poor drainage systems in urban areas, especially during rainy seasons, and irrigation ditches in farmland provide abundant mosquito breeding places [1-3]. Tanzania spends a low share of its

\footnotetext{
* Correspondence: kwekae@tpri.or.tz

${ }^{2}$ Department of Medical Parasitology and Entomology, School of Medicine, Catholic University of Health and Allied Sciences, P.O. Box 1464, Mwanza, Tanzania

${ }^{4}$ Division of Livestock and Human Diseases Vector Control, Mosquito Section, Tropical Pesticides Research Institute, P.O. Box 3024, Arusha, Tanzania

Full list of author information is available at the end of the article
}

gross domestic product $(7.2 \%)$ on health, with a meagre public expenditure of $39 \%$ for health costs [4]. Vectorborne diseases affecting people in Tanzania are malaria, filariasis, dengue, chikungunya and other arboviruses [5]. Malaria remains the deadliest vector-borne disease despite long-term control efforts [6]. Among the mosquitoborne vectors, Ae. aegypti (L.), a vector of dengue fever, is prevalent in the tropics and sub-tropics and is closely associated with human habitats outside its native range of Africa [7]. Culex pipiens pallens (Coquillett) is a vector of the western Nile virus and is distributed throughout Africa, the Middle East and Asia [8]. The 
complex sibling species of An. gambiae which transmit malaria worldwide have been described [9]. All of these vector-borne diseases occur mainly in tropical countries where more than two billion people live in endemic regions [10]. The approaches to combating vector-borne diseases relies on the interruption of the disease transmission cycle by either targeting the adult or larvae through spraying breeding sites or targeting adults using insecticides [11]. Synthetic pesticides have been extensively used for mosquito control by either killing the vectors, preventing adult mosquitoes from biting humans or by killing mosquito larvae at breeding sites $[12,13]$. However, the development of resistance to different classes of synthetic insecticides such as pyrethroids, organophosphates, organochlorides and carbamates has drawn attention to the search of alternative methods of control [14]. The toxicity of the available chemical insecticides, their high operational cost and the subsequent environmental pollution have caused the need for developing alternative approaches to control vector-borne diseases [15]. Plant extracts with proven mosquito control potential can be used in place of synthetic insecticides, either as insecticides for killing larvae or adult mosquitoes or as repellents for protection against mosquito bites. Amongst them, essential oils have gained a special interest due to their insecticidal properties [16] andin recent years, have proved to be potentially useful sources of bioactive compounds against mosquito larvae [17]. Essential oils are composed of isoprenoid compounds, mainly monoterpene carriers of smell in the aromatic plants, such as sesquiterpenes alcohols identified from Chamaecyparis obtusa leaf oil and various monoterpene components derived from Thuja orientalis [18].

A number of studies have been conducted on essential oils to determine their larvicidal and repellency activities. Cinnamon umzeylanicum, Cymbopogon citrates, Lavandula angustifolia, Tanacetum vulgare, Rubdosia melissoides, Eugenia caryophyllata, Ocimum spp., Gaultheria procumbens, Cuminum cymium, Bunium persicum, Trachyspermum ammi, Foeniculum vulgare, Abelmoschus moschatus, Cedrus spp. and Piper spp. have been found to be effective for pest control [19]. Other essential oils such as lemon grass (Cymbopogon winteriana), eucalyptus (Eucalyptus globules), rosemary (Rosemarinus officinalis), vetiver (Vetiveria zizanoides), clove (Eugenia caryophyllus) and thyme (Thymus vulgaris) are known for their pest control properties [19]. Another study, conducted on the repellent effect of essential oils from Cymbopogon spp., Ocimum spp., and Eucalyptus spp. showed their strong repellency against malaria vectors and other mosquitoes [12].

Apart from essential oils, extracts prepared from Tanzanian plants have been evaluated for their larvicidal activity. For instance, extracts from Annona muricata, Annona senegalensis and Annona squamosa were active against Culex quinquefasciatus, which demonstrated that extracts of Annona species grown in Tanzania could be potential anti-mosquito agents [20]. In spite of the antimosquito activities of several studied species of plants, relatively little work has been done on the larvicidal activities of essential oils extracted from spices, such as clove and cinnamon. A recent study carried out in Nigeria assessed the activity of clove essential oils against Ae. aegypti and $C x$. quinquefasciatus and achieved over 85\% larval mortality within 24-hourspost-exposure [21]. Meanwhile, in Thailand, lemongrass and clove essential oils were effective in causing mortality for all larval stages of $A n$. dirus and Ae. aegypti [22].

The aim of this study was to determine the active ingredients, and larvicidal activities of clove (Family: Myrtaceae) and cinnamon (Family: Lauraceae) essential oils and their blend against insectary-reared Anopheles gambiae (s.s.) larvae and $A n$. arabiensis larvae from wild populations.

\section{Methods \\ Collection of essential oils}

Clove and cinnamon essential oils were purchased from Market Street in Mwanza, Tanzania. These oils were obtained raw through a distillation unit. There was no addition of any other contents.

\section{Larvae collection and rearing}

Wild larvae of An. gambiae (s.l.) were collected from Magu district in Mwanza Region, North-Western Tanzania. Larvae were sampled from irrigated rice fields using a standard dipper (350 ml) [23] and transported to the insectary. Larvae were reared on yeast powder as a food source in the mosquito insectary unit at the Mwanza Research Centre, National Institute for Medical Research (NIMR), Tanzania. Colonies were maintained at $27 \pm 2{ }^{\circ} \mathrm{C}$, with a $12 \mathrm{~h}$ light: 12 -h dark cycle.

Insectary reared third instars An. gambiae (s.s.) (Kisumu strain - insecticide susceptible strain) larvae and thirdinstar An. arabiensis field population larvae (insecticides tolerant population) were tested against essential oils in different concentrations. Larvae collected from wild population showed tolerance to pyrethroids and DDT in previous studies comprised of $91 \%$ An. arabiensis and the rest of An. gambiae (s.s.) and An. funestus [24]. The main source of insecticide resistance in this study site is the use of different insecticide classes with different mixtures in cultivating crops and the wide coverage of LLINs in the area [24].

\section{Mosquito larvicidal tests}

Larvicidal tests were carried out based on the WHO standardized procedures and guidelines for larvicidal test 
method [25]. The initial screening was conducted using the selected plant extracts with different dosages ranging from $2 \mathrm{mg} / \mathrm{ml}$ to $100 \mathrm{mg} / \mathrm{ml}$. The dosages causing mortality above $10 \%$ were selected for trial and ranged from $5 \mathrm{mg} / \mathrm{ml}$ to $80 \mathrm{mg} / \mathrm{ml}$. Stock solutions of essential oils were prepared in acetone at an initial concentration of $160 \mathrm{mg}$ in $2 \mathrm{ml}(80 \mathrm{mg} / \mathrm{ml})$. Then, two-fold dilutions were prepared in $1 \mathrm{ml}$ acetone in each of the test cups to get a total of five different concentrations ranging from $80,40,20,10$, and $5 \mathrm{mg} / \mathrm{ml}$ of the essential oils.

Twenty third-instar larvae were placed in plastic cups containing distilled water for $1 \mathrm{~h}$ to reduce the stress. Thereafter $0.2 \mathrm{ml}$ of each of the stock solution was added to their respective cups to make test solutions at concentrations ranging from $800,400,200,100$ and $50 \mu \mathrm{g} / \mathrm{ml}$ in their respective plastic cups containing the 20 test larvae each, which were used for the larvicidal tests. A negative control containing $19.8 \mathrm{ml}$ of distilled water and $0.2 \mathrm{ml}$ acetone with twenty third-instar mosquito larvae was also prepared. Each test comprised of four replicates of five concentrations (800, 400, 200, 100 and $50 \mu \mathrm{g} / \mathrm{ml})$. Each sample of the essential oil was tested three times on different days in the four replicates. Acetone was used to solubilize the essential oil in the water. During the testing time, after $24 \mathrm{~h}$ of monitoring mosquito larvae, they were provided with yeast powder and monitored for $72 \mathrm{~h}$.

Experiments were carried out under laboratory conditions $25-28{ }^{\circ} \mathrm{C}$ and a photoperiod of $12 \mathrm{~h}$ light followed by $12 \mathrm{~h}$ dark (12 L: 12D) against laboratory-reared third instar larvae of Anopheles gambiae (s.s.) and wild population of An. arabiensis. Mortality was recorded after $24 \mathrm{~h}$ of exposure, then larval food (yeast powder for An. gambiae) was added for those alive after $24 \mathrm{~h}$, next mortality was recorded after $48 \mathrm{~h}$ and $72 \mathrm{~h}$.

Larvae were considered dead when they were moribund or failed to do any movement. The dead larvae were counted, and the average percentage mortality was calculated. Data were adjusted for control mortality using Abbott's formula when mortality in the control sets between $5 \%$ and $20 \%$ [26].

$$
\text { Mortality }(\%)=\frac{X-Y}{X} \times 100
$$

where $\mathrm{X}$ was the percentage of survival in the control larvae population and $\mathrm{Y}$ was the percentage survival in the treated larvae population. The same formula was applied to both laboratory and wild larvae population.

Lethal dosages killing 50\% $\left(\mathrm{LC}_{50}\right)$ and $95 \%\left(\mathrm{LC}_{95}\right)$ of the population exposed were calculated using probit regression analysis in SPSS version 17.0 for windows (SPSS Inc., Chicago, IL, USA). A Student's $t$-test was used to compare the mortality of larvae between concentrations for wild and laboratory-reared larvae in each evaluated extract and in blends.

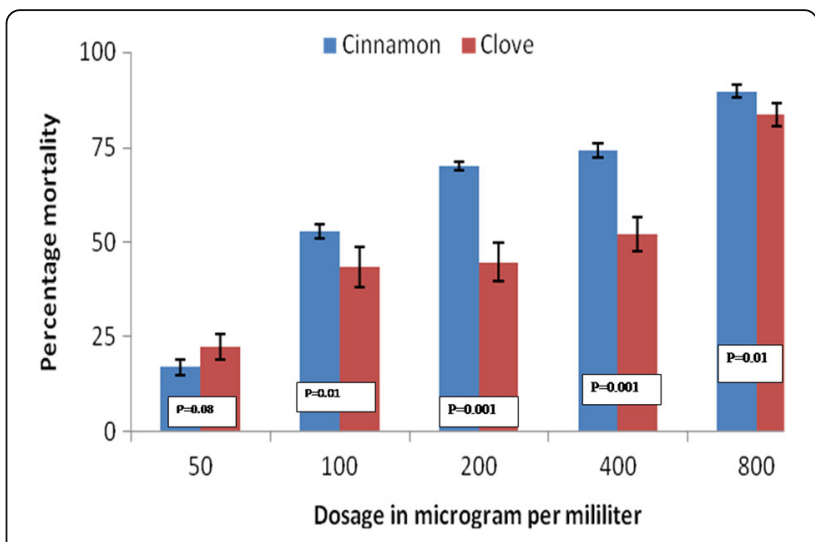

Fig. 1 Larvae percentage mortality post-exposure in cinnamon and clove oils in different concentrations for wild-collected mosquitoes

\section{Chromatographic analysis}

The identification of the essential oil components was carried out by high-resolution gas chromatography analysis, in the analytical laboratory, at Tropical Pesticides Research Institute (TPRI)-Arusha. The injection volume was $2 \mu \mathrm{l}$ composed of $1.6 \mu \mathrm{l}$ of a solution of essential oil $(40 \mu \mathrm{g} / \mathrm{ml})$ and $0.4 \mu \mathrm{l}$ of a solution of hydrocarbon series of $\mathrm{C}_{7}-\mathrm{C}$, as an internal standard, both in n-hexanes as a solvent. The gas chromatography coupled with mass spectrometry-GC-MS-system used consisted of a gas chromatograph, Thermo Scientific ${ }^{\circ}$ Ultra GC coupled to a mass spectrometer, Thermo Scientific ${ }^{\circ}$. The fused silica capillary column used was a DB-5 J \& W Scientific $(30 \mathrm{~m} \times 0.25 \mathrm{~mm} \times 0.25 \mathrm{~mm})$. Helium was the carrier gas, and the column temperature program was increased by $3{ }^{\circ} \mathrm{C}$ per minute between 60 and $240{ }^{\circ} \mathrm{C}$. The mass spectra were obtained at $70 \mathrm{eV}$ at a scan rate of 0.84 scans/s and at the range $\mathrm{m} / \mathrm{z} 40-500$. The retention times of sample components and a mixture of $n$-alkanes from $C_{7}-C$,

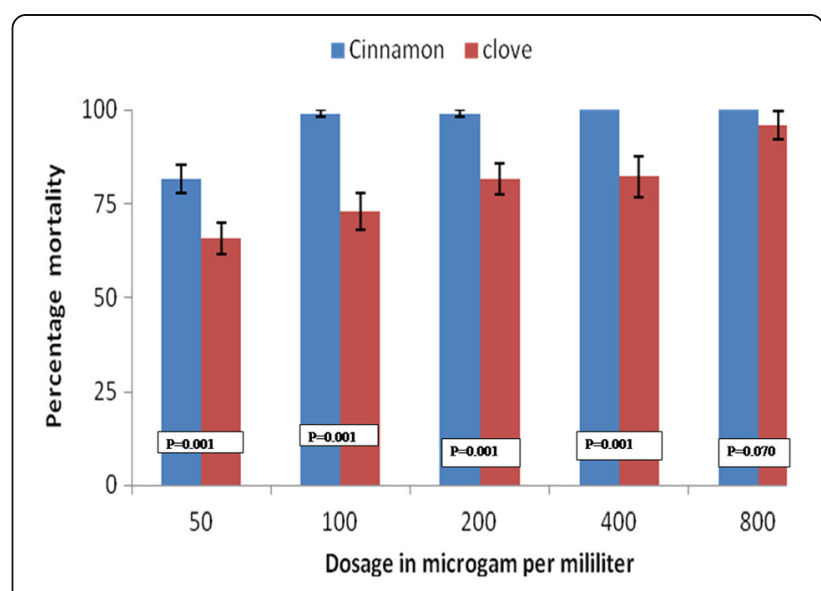

Fig. 2 Larvae percentage mortality post-exposure in cinnamon and clove oils in different concentrations for laboratory-reared mosquitoes 
Table 1 Mortality effect of clove and cinnamon essential oils against wild larvae with their $L C_{50}$ and $L C_{95}$ values

\begin{tabular}{llllll}
\hline Essential oil & Time $(\mathrm{h})$ & $\mathrm{LC} C_{50}(\mu \mathrm{g} / \mathrm{ml})$ & $95 \% \mathrm{Cl}$ & $\mathrm{LC}(\mu 5 \mathrm{~g} / \mathrm{ml})$ & $95 \% \mathrm{Cl}$ \\
\hline Clove & 24 & 159.1 & $129.7-194.0$ & 3950.1 & $2707.1-6311.2$ \\
& 48 & 229.9 & $188.5-281.4$ & 5707.6 & $3795.2-9488.8$ \\
& 72 & 246.1 & $201.9-301.6$ & 6110.8 & $4043.0-10,226.1$ \\
Cinnamon & 24 & 131.459 & $119.8-143.9$ & 1295.96 & $1128.0-1508.6$ \\
& 48 & 129.668 & $118.2-141.9$ & 1278.3 & $1113.5-1486.7$ \\
& 72 & 115.536 & $105.1-126.7$ & 1139.0 & $994.0-1321.6$ \\
\hline
\end{tabular}

coinjected into the GC-MS system under the same temperature program was used for the calculation of the Arithmetic Retention Index - AI - and the Kovats Retention Index (KI) [27]. Identification of components was based on several methods: the calculated AI and KI and mass spectra [28].

\section{Results}

A total of 2400 larvae were used for testing in different concentrations. For the laboratory-based susceptible colony, 1200 An. gambiae (s.s.) larvae were used, where 240 larvae in each of the five different concentrations were used. The similar wild population of An.arabiensis larvae collected from wild was tested in the same scenario as the laboratory-based population of An. gambiae (s.s.). The larvicidal activity of essential oils of cloves and cinnamon against laboratory and wild collected larvae were found to be dosage-dependent with a higher mortality observed for cinnamon essential oils (Figs. 1, 2). The difference in mortality between cinnamon and clove essential oils were statistically significant in each concentration for wild-collected and laboratory colonies except for the concentration of $800 \mu \mathrm{g} / \mathrm{ml}$ (Figs. 1, 2). The lethal dose to kill $50 \%$ and $95 \%$ of larvae population increased with the time of exposure for both laboratoryreared and wild population larvae (Tables 1, 2). The larvicidal activity of essential oil blends (of cloves and cinnamon) against Anopheles gambiae (s.s.) appeared to be higher in blends with higher proportions of cinnamon than clove essential oils (Figs. 3, 4). The chemical ingredients and composition of clove and cinnamon essential oils were found to be varying. The main active ingredient of cinnamon essential oils were Eugenol (96.5\%) and
$\beta$-Linalool (3.5\%) (Table 3) while the main active ingredient of clove essential oils were eugenol (99.14\%), phenol, 2-methoxy-4-(2-propenyl)-,acetate (0.45\%), phenol, 2-methoxy-4-(1-propenyl)- (0.17\%), methyl salicylate (0.13) and bicyclo [7.2.0] undec-4-ene, 4,11,11-trimethyl8-methylene-,[1R-(1R*,4Z, 9S*)]- (0.12\%) (Table 4).

\section{Discussion}

Here, we showed the pronounced larvicidal activity of the investigated essential oils against wild larvae of An.arabiensis and laboratory-reared larvae of $A n$. gambiae (s.s.) despite their different chemical components. Clove and cinnamon essential oils under investigation were found to have one common main active ingredient, Eugenol (4-alil-2-methoxyphenol). A similar chemical composition has been described for these essential oils with different extraction techniques [29]. The mortality caused by cinnamon was found to be higher than that caused by the clove essential oils, which might be attributed to the presence of $\beta$ linalool, found in cinnamon essential oils although in a small proportion. In a previous study, Ocimum suave essential oils extracts containing Eugenol as the highest occurring active ingredient had the lowest mortality in grain pests when tested in the absence of $\beta$-linalool than with $\beta$-linalool [30]. In previous reports, Eugenol mostly showed a high adult repellency effect rather than inducing larval mortality [31].

The mortality caused by clove essential oils was highly dosage-dependent with a higher mortality seen with the use of higher dosages. This trend was similar to another study conducted using the essential oils from Terebinthifolia radii [32]. In spite of being dosage-dependent, the

Table 2 Mortality effect of clove and cinnamon essential oils against laboratory-reared larvae with their $L_{50}$ and $L_{95}$ values

\begin{tabular}{llllll}
\hline Essential oil & Time $(\mathrm{h})$ & $\mathrm{LC} \mathrm{C}_{50}(\mu \mathrm{g} / \mathrm{ml})$ & $95 \% \mathrm{Cl}$ & $\mathrm{LC} 95(\mu \mathrm{g} / \mathrm{ml})$ & $95 \% \mathrm{Cl}$ \\
\hline Clove & 24 & 17.527 & $1.38-48.29$ & 2374.06 & $766.08-46,983.67$ \\
& 48 & 19.56 & $1.68-52.42$ & 2649.45 & $842.39-56,349.62$ \\
Cinnamon & 72 & 8.605 & $0.34-29.24$ & 1165.53 & $428.91-12,406.62$ \\
& 24 & 11.788 & $5.67-18.87$ & 115.15 & $86.85-158.69$ \\
& 48 & 10.46 & $4.90-17.04$ & 102.18 & $75.77-142.14$ \\
& 72 & 12.314 & $6.07-19.43$ & 120.28 & $90.97-166.96$ \\
\hline
\end{tabular}




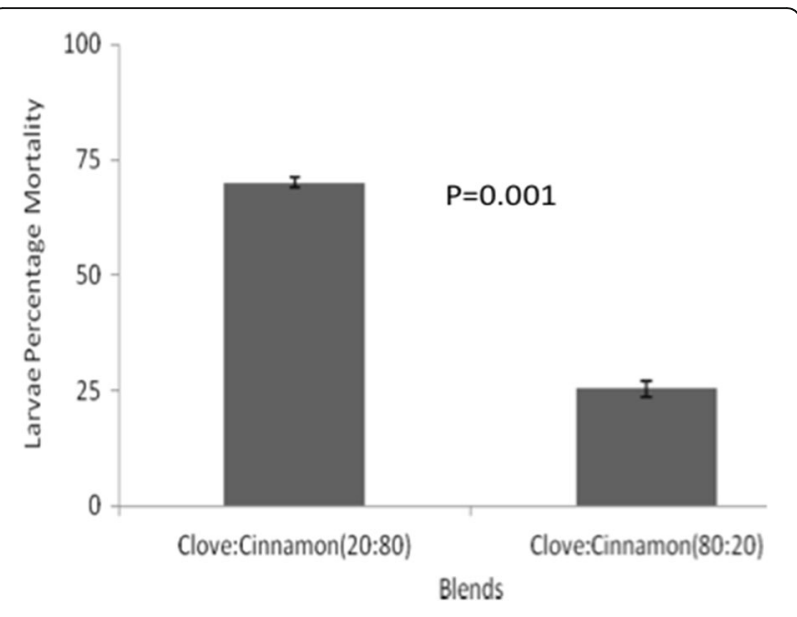

Fig. 3 Percentage mortality of wild-collected larvae in two blends

mortality of the wild collected larvae was lower than that of laboratory-reared larvae. This may be explained by the fact that wild larvae have already been exposed to different insecticides and other environmental contaminants including heavy metals, which have caused them to be tolerant to different insecticides, unlike to the laboratory colonies $[33,34]$. The mortality caused by the cinnamon essential oils had a similar trend as clove essential oils but higher mortalities, both in the laboratory and in the wild collected larvae, was observed with cinnamon essential oils.

The mortality of larvae caused by the two blends of cinnamon and clove in both the laboratory-reared and the wild larvae had a similar trend, with the blend having a higher proportion of cinnamon causing a higher mortality than the one with a higher proportion of clove. The high mortality with the increased proportion of cinnamon is explained by the presence of $\beta$ -

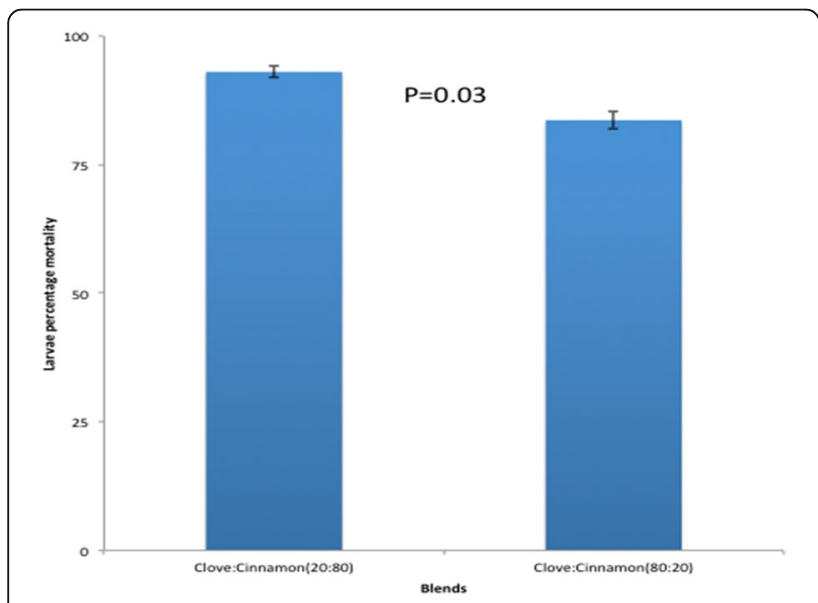

Fig. 4 Percentage mortality of laboratory-reared larvae in two blends
Table 3 Chemical composition of the cinnamon essential oil

\begin{tabular}{lll}
\hline Compound & RT (min) & \% composition \\
\hline$\beta$-Linalool & 5.666 & 3.5 \\
Eugenol & 10.483 & 96.5 \\
\hline
\end{tabular}

Abbreviation: $R T$ retention time in minutes

linalool in this essential oil. The mortality among susceptible laboratory larvae was higher than among wild-collected larvae due to the reported resistance gene dominance in wild populations [35]. This indicates that, if this active ingredient of cinnamon is appropriately synthesized and utilized for control purposes, it might have a great value in the existing vector control measures against insecticide tolerant vectors. In general, in agreement with the references quoted above, the effect of $\beta$-linalool component in cinnamon essential oil is definitely strongly associated with the mortality caused by this essential oil, either in the laboratory-reared or among the wild -collected larvae.

In spite of the great efficacy showed on mosquito larval mortality in different concentrations of tested plant-basedextracts, the main challenges remain the stability of the compounds in the natural environment. If collaboration with industries and chemists could be brought together, more stable compounds could be synthesized, such as to avoid the effect of sunlight, which causes degradation and form secondary metabolites which might be non-toxic and add no value in the fighting against malaria vectors.

\section{Conclusion}

These essential oils of clove and cinnamon have shown to have a larvicidal effect which is concentrationdependent for both the laboratory-reared and the wild collected larvae. The proportion of the active ingredients in the cinnamon and clove essential oils blends have different mortality rateS among the laboratory-reared and the wild collected larvae. The extracted compounds can be useful if observed efficacy can be extended to small-scale trials with more synthetic compounds of similar structures.

Table 4 Chemical composition of clove essential oil

\begin{tabular}{lll}
\hline Compound & RT (min) & $\%$ composition \\
\hline Methyl salicylate & 8.050 & 0.13 \\
$\begin{array}{l}\text { Bicyclo [7.2.0]undec-4-ene, 4,11,11- } \\
\text { trimethyl-8-methylene-,[1R-(1 R*,4Z, 95*)]- }\end{array}$ & 10.142 & 0.12 \\
Eugenol & 10.493 & 99.14 \\
Phenol, 2-methoxy-4-(1-propenyl)- & 11.281 & 0.17 \\
Phenol, 2-methoxy-4-(2-propenyl)-, acetate & 13.065 & 0.45 \\
\hline
\end{tabular}

Abbreviation: $R T$ retention time in minutes 


\section{Acknowledgements}

Authors wish to thank everyone involved in the accomplishment of this study. Authors are thankful to the staff members of National Institute of Medical Research (NIMR) Insectary for their assistance. Thanks to Mr. Joseph Malulu for his assistance in operating GC-MS for chemical analysis of essential oils. Authors sincerely thank the Higher Education Students' Loans Board for financing AT studies at CUHAS.

\section{Funding}

This study was supported by the Higher Education Students' Loans Board granted to AT.

\section{Availability of data and materials}

The data supporting the conclusions of this article are included within the article. The raw data used in the present study are available from the corresponding author on request (kwekae@tpri.or.tz).

\section{Authors' contributions}

AT and EJK conceived the study, prepared protocols, analysed and interpreted the data and drafted the manuscript. AT did data collection and conducted experiments. EJK, AM, HDM and DM revised and edited the manuscript to final form. All authors read and approved the final manuscript.

\section{Ethics approval and consent to participate}

Ethical approval was obtained from the joint Catholic University of Health and Allied Sciences (CUHAS) /Bugando Medical Centre (BMC) institutional review board.

\section{Consent for publication}

Not applicable.

\section{Competing interests}

The authors declare that they have no competing interests.

\section{Publisher's Note}

Springer Nature remains neutral with regard to jurisdictional claims in published maps and institutional affiliations.

\section{Author details \\ ${ }^{1}$ School of Pharmacy, Catholic University of Health and Allied Sciences, P.O. Box 1464, Mwanza, Tanzania. ${ }^{2}$ Department of Medical Parasitology and Entomology, School of Medicine, Catholic University of Health and Allied Sciences, P.O. Box 1464, Mwanza, Tanzania. ${ }^{3}$ National Institute for Medical Research, Mwanza Research Centre, Mwanza, Tanzania. ${ }^{4}$ Division of Livestock and Human Diseases Vector Control, Mosquito Section, Tropical Pesticides Research Institute, P.O. Box 3024, Arusha, Tanzania.}

Received: 23 March 2017 Accepted: 29 August 2017

Published online: 06 September 2017

\section{References}

1. Prabhu K, Murugan K, Nareshkumar A, Ramasubramanian N, Bragadeeswaran S. Larvicidal and repellent potential of Moringa oleifera against malarial vector, Anopheles stephensi Liston (Insecta: Diptera: (ulicidae). Asian Pac J Trop Biomed. 2011:1:124-9.

2. Kweka EJ, Mazigo HD, Himeidan YE, Morona D, Munga S. Urbanization, climate change and malaria transmission in sub-Saharan Africa. In: Dhang P, editor. Climate change impacts on urban pests. Manila: CABI Climate Change Series; 2016. p. 141.

3. Kweka EJ, Zhou G, Lee M-C, Gilbreath TM, Mosha F, Munga S, et al. Evaluation of two methods of estimating larval habitat productivity in western Kenya highlands. Parasit Vectors. 2011;4:110

4. Brinda EM, Andrés RA, Enemark U. Correlates of out-of-pocket and catastrophic health expenditures in Tanzania: results from a national household survey. BMC Int Health Hum Rights. 2014;14:5-5.

5. Chipwaza B, Mugasa JP, Selemani M, Amuri M, Mosha F, Ngatunga SD, et al. Dengue and chikungunya fever among viral diseases in outpatient febrile children in Kilosa District hospital, Tanzania. PLoS Negl Trop Dis. 2014;8:e3335.

6. Acheson ES, Plowright AA, Kerr JT. Where have all the mosquito nets gone? Spatial modelling reveals mosquito net distributions across Tanzania do not target optimal Anopheles mosquito habitats. Malar J. 2015;14:322.
7. Tan C-H, Wong P-SJ, Li M-ZI, Yang H-T, Chong C-S, Lee LK, et al. Membrane feeding of dengue patient's blood as a substitute for direct skin feeding in studying Aedes-dengue virus interaction. Parasit Vectors. 2016;9:1-11.

8. Harbach RE. Culex pipiens: species versus species complex - taxonomic history and perspective. J Am Mosq Control Assoc. 2012;28:10-23.

9. Coetzee M, Hunt RH, Wilkerson R, Della Torre A, Coulibaly MB, Besansky NJ. Anopheles coluzzii and Anopheles amharicus, new members of the Anopheles gambiae complex. Zootaxa. 2013;3619:246-74.

10. WHO. Factsheet on the world malaria. Report 2015. Geneva: World Health Organisation; 2015.

11. Joseph CC, Ndoile MM, Malima RC, MHH N. Larvicidal and mosquitocidal extracts, a coumarin, isoflavonoids and pterocarpans from Neorautanenia mitis. Trans The Royal Soc TropMed Hyg. 2004;98:451-5.

12. Rehman JU, Ali A, Khan IA. Plant based products: use and development as repellents against mosquitoes: a review. Fitoterapia. 2014;95:65-74.

13. Manimaran A, Cruz MMJJ, Muthu C, Vincent S, Ignacimuthu S. Larvicidal and knockdown effects of some essential oils against Culex quinquefasciatus Say, Aedes aegypti (L.) and Anopheles stephensi (Liston). Adv Bioscience and Biotechnol. 2012:3:855-62.

14. Ochomo E, Bayoh MN, Brogdon WG, Gimnig JE, Ouma C, Vulule JM, et al. Pyrethroid resistance in Anopheles gambiae s.S. and Anopheles arabiensis in western Kenya: phenotypic, metabolic and target site characterizations of three populations. Med Vet Entomol. 2013;27:156-64.

15. Verlé $P$, Lieu TTT, Kongs A, Van der Stuyft P, Coosemans M. Control of malaria vectors: cost analysis in a province of northern Vietnam. Trop Med \& Int Health. 1999:4:139-45.

16. Mukandiwa L, Eloff JN, Naidoo V. Repellent and mosquitocidal effects of leaf extracts of Clausena anisata against the Aedes aegypti mosquito (Diptera: Culicidae). Environ Sci Pollut Res Int. 2016;23:11257-66.

17. Kweka EJ, Lima TC, Marciale CM, de Sousa DP. Larvicidal efficacy of monoterpenes against the larvae of Anopheles gambiae. Asian Pac J Trop Biom. 2016:6:290-4

18. Paiva P, Napoleão T, Santos N, Correia M, Navarro D, Coelho L. Plant compounds with Aedes aegypti larvicidal activity and other biological properties. In: Bioprocess sciences and technology. New York: Nova Publishers Inc; 2011. p. 269-94

19. Govindarajan M. Chemical composition and larvicidal activity of leaf essential oil from Clausena anisata (Willd.) Hook. f. Ex Benth (Rutaceae) against three mosquito species. Asian Pac J Trop Med. 2010;3:874-7.

20. Kihampa C, Joseph CC, Nkunya MH, Magesa SM, Hassanali A, Heydenreich $M$, et al. Larvicidal and IGR activity of extract of Tanzanian plants against malaria vector mosquitoes. J Vector Borne Dis. 2009;46:145-52.

21. Fayemiwo KA, Adeleke MA, Okoro OP, Awojide SH, Awoniyi IO. Larvicidal efficacies and chemical composition of essential oils of Pinus sylvestris and Syzygium aromaticum against mosquitoes. Asian Pac J Trop Biomed. 2014;4:30-4.

22. Soonwera M, Phasomkusolsil S. Effect of Cymbopogon citratus (lemongrass) and Syzygium aromaticum (clove) oils on the morphology and mortality of Aedes aegypti and Anopheles dirus larvae. Parasitol Res. 2016;115:1691-703.

23. WHO: Manual on practical entomology in malaria. Part II. Methods and techniques. Geneva, Switzerland: World Health Organization; 1975.

24. Philbert A, Lyantagaye SL, Pradel G, Ngwa CJ, Nkwengulila G. Pyrethroids and DDT tolerance of Anopheles gambiae s.l. from Sengerema District, an area of intensive pesticide usage in north-western Tanzania. Tropical Med Int Health. 2017;22:388-98.

25. WHO. Guidelines for laboratory and field testing of mosquito larvicides. Vol. WHO/CDS/WHOPES/GCPP/2005. Geneva: World Health Organisation; 2005.

26. Abbott W. A method of computing the effectiveness of an insecticide. J Econ Entomol. 1925;18:265-7.

27. Prakash A, Rao J. Botanical pesticides in agriculture. New York, USA: CRC press: Lewis Publisher; 1996.

28. Adams RP. Identification of essential oils by ion trap mass spectroscopy: Harcourt Brace Jovanovich Publisher, San Diego, USA: Academic Press; 2012.

29. Cansian RL, Vanin AB, Orlando T, Piazza SP, Puton BM, Cardoso Rl, et al. Toxicity of clove essential oil and its ester eugenyl acetate against Artemia salina. Braz J Biol. 2017;77:155-61.

30. Weaver DK, Dunkel FV, Ntezurubanza L, Jackson LL, Stock DT. The efficiency of linalool, a major component of freshly milled Ocimum canum (Sims) (Lamiaceae), for protection against stored product Coleoptera. J Stored Prod Res. 1991;8:311-23.

31. Huang TH, Tien NY, Luo YP. An in vitro bioassay for the quantitative evaluation of mosquito repellents against Stegomyia aegypti (Aedes aegypti) mosquitoes using a novel cocktail meal. Med Vet Entomol. 2015;29:238-44. 
32. Kweka EJ, Nyindo M, Mosha F, Silva AG. Insecticidal activity of the essential oil from fruits and seeds of Schinus terebinthifolia Raddi against African malaria vectors. Parasit Vectors. 2011;4:129.

33. Mireji PO, Keating J, Hassanali A, Impoinvil DE, Mbogo CM, Muturi MN, et al. Expression of metallothionein and alpha-tubulin in heavy metal-tolerant Anopheles gambiae sensu stricto (Diptera: Culicidae). Ecotoxicol Environ Saf. 2010;73:46-50

34. Mireji PO, Keating J, Hassanali A, Mbogo CM, Muturi MN, Githure Jl, et al. Biological cost of tolerance to heavy metals in the mosquito Anopheles gambiae. Med Vet Entomol. 2010;24:101-7.

35. Protopopoff N, Wright A, West PA, Tigererwa R, Mosha FW, Kisinza W, et al, Combination of insecticide treated nets and indoor residual spraying in northern Tanzania provides additional reduction in vector population density and malaria transmission rates compared to insecticide treated nets alone: a randomised control trial. PLoS One. 2015;0:e0142671.

Submit your next manuscript to BioMed Central and we will help you at every step:

- We accept pre-submission inquiries

- Our selector tool helps you to find the most relevant journal

- We provide round the clock customer support

- Convenient online submission

- Thorough peer review

- Inclusion in PubMed and all major indexing services

- Maximum visibility for your research

Submit your manuscript at www.biomedcentral.com/submit
C) Biomed Central 